\title{
Hacia una república conservadora: el programa político del Partido Agrario Español
}

\author{
LUIS TeófILo GIL CuadRado \\ Doctor en $\mathrm{H} .{ }^{\text {a }}$ Universidad Complutense de Madrid

\begin{abstract}
Towards a conservative Republilc: the political program of the Spanish Agrarian Party
\end{abstract}

RESUMEN

El Partido Agrario Español (PAE), fundado en enero de 1934 y presidido por José Martínez de Velasco, representó, dentro de la II República española, una alternativa conservadora y, al tiempo, leal al régimen. El programa político del PAE aceptaba la República - a diferencia de otros partidos derechistas del momento, como la CEDA y los monárquicos-y defendía la unidad nacional, el establecimiento de una segunda Cámara legislativa, la protección de la agricultura y la industria mediante aranceles, el libre comercio dentro de las fronteras nacionales y la revisión de algunas leyes del primer bienio como la Reforma Agraria de 1932. El objetivo era la configuración de una República conservadora distinta, en aspectos fundamentales, a la diseñada por la Constitución de 1931 y la legislación del bienio social-republicano.

PALABRAS CLAVE: Agrarismo; Derecha; Segunda República Española; Partidos políticos; Partido Agrario Español.

\section{ABSTRACT}

The Spanish Agrarian Party (Partido Agrario Español, PAE), founded in january of 1934 and presided by José Martínez de Velasco, was, in the political life of the Spanish Second Republic, a conservative and republican option. The agrarian program accepted the republican regime -in opposition to other conservative parties, like the CEDA or the monarchists - and defended the national union, the establishment of a Senate, the protection of the national agriculture and industry trough tariffs, the free trade in the Spanish market and the revision of some laws voted in the first biennium like the Agrarian Reform, promulgated in 1932. The idea was to establish a conservative Republic, different, in some fundamental aspects, of the regime designed by the Constitution of 1931 and the legislation approved during the socialist-republican biennium.

KEYWORDS:

Agrarism; Conservatives; Second Spanish Republic; Political parties; Spanish Agrarian Party. 
Dentro del panorama político de la II República, el Partido Agrario Español (PAE), fundado en enero de 1934 y presidido por José Martínez de Velasco, representó una alternativa conservadora y, al tiempo, fiel al régimen nacido el 14 de abril de $1931^{1}$. Su objetivo fue la configuración de una República conservadora y de orden, distinta en aspectos fundamentales de la resultante de la Constitución de 1931 y de las leyes complementarias promulgadas por las Cortes Constituyentes. Coincidió en esa pretensión con otras fuerzas políticas, como el Partido Republicano Conservador (PRC) de Miguel Maura, el Partido Republicano Progresista (PRP) de Niceto Alcalá-Zamora y el Partido Republicano Liberal Demócrata (PRLD) de Melquíades Álvarez². De esta manera, el PAE ocupó, en el espectro político de aquellos años, una situación intermedia entre el centrismo del Partido Republicano Radical (PRR) y la derecha católica representada por la CEDA, como describió quien fuera vicepresidente del partido y una de sus figuras más populares, Antonio Royo Villanova:

«Los agrarios, ni podemos confundirnos con los demás partidos gubernamentales ni podemos tampoco separarnos de los que con nosotros tienen tantas cosas en común que defender. No podemos confundirnos con los radicales de Lerroux, porque ellos votaron el artículo 26 de la Constitución y nosotros no; porque ellos votaron el Estatuto de Cataluña y nosotros no. No podemos confundirnos con nuestros amigos de la CEDA, porque ellos se han declarado regionalistas y nosotros no, y porque tampoco tienen la fe que nosotros en la libertad, en la democracia y en el Parlamento. Nosotros, sin embargo, tenemos de común con todas las minorías gubernamentales y con todas las derechas la defensa de la Patria. Tenemos de común con todos los que fuimos a las elecciones [de 1933] la bandera de la revisión constitucional. Tenemos de común con los republicanos de Lerroux y con los de Melquíades Álvarez la defensa de la libertad. Con los que no tenemos nada de común son con los nacionalistas catalanes, vascos o gallegos, que niegan a la Patria, ni con los socialistas, que niegan a la libertad»3.

El único documento programático publicado por el PAE fue su manifiesto fundacional, aparecido en la prensa el 1 de febrero de 19344. Además de en dicho texto, el ideario del partido sobre la organización del Estado, la política exterior, la economía o la sociedad fueron apareciendo en sus órganos de prensa - Horizontes y Boletín del Partido Agrario Español-y en los discursos y declaraciones de sus dirigentes. La exposición de aquél es el objeto de las siguientes líneas.

\footnotetext{
1 Acerca del PAE, ver Rueda Hernanz, G.: «El Partido Agrario Español (1934-1936). Análisis sociológico de la sección valenciana y estudio comparativo con la agrupación madrileña del Partido Republicano Radical», Revista de Estudios Políticos, 206-207, (1976), pags. 303-323 y GIL CuADRADO, L. T.: «El Partido Agrario Español (1930-1936). Supuestos para una investigación», Aportes, 43-2, (2000), pags. 61-78.

2 Sobre estos tres partidos, ver IÑIGo FERnÁNDEZ, L.: La derecha liberal en la Segunda República Española, Madrid, UNED, 2000.

3 Royo Villanova, A.: «El Partido Agrario», Horizontes, 21 de enero de 1935.

4 Ahora, $A B C$ y El Debate, 1 de febrero de 1934. Publicado posteriormente como PARTIDO AGRARIO ESPAÑOL: Programa provisional elaborado por la Minoría Agraria del Congreso de los Diputados en tanto se reúna la asamblea nacional, Madrid, Ernesto Giménez, 1934.
} 


\section{ORGANIZACIÓN DEL ESTADO}

EI PAE, en su manifiesto fundacional, aceptaba la República, aunque proponía una reforma de la Constitución consistente en la revisión de aquellos artículos «que atentan a la conciencia religiosa del pueblo español o imponen principios de socialización» y en la «instauración de una segunda Cámara en que las fuerzas sociales tengan orgánica representación»5.

La aceptación de la República provocó que la prensa monárquica considerara a los agrarios traidores al electorado derechista que les había elegido. Se daba la circunstancia, de que la mayoría de los miembros más destacados del PAE habían militado en los extintos partidos monárquicos, especialmente en el liberal. Así, Martínez de Velasco había formado parte de los liberales demócratas de Manuel García Prieto, ocupando la subsecretaría de Gracia y Justicia en el último Gobierno de la Monarquía; otras figuras agrarias destacadas, como Royo Villanova y José María Cid, procedían de la Izquierda Liberal de Santiago Alba.

Royo Villanova propuso como programa de la República conservadora anhelada por su partido el Estatuto Jurídico promulgado el 14 de abril de 1931 por el Gobierno provisional: libertad de cultos y de conciencia; libertad individual, de asociación y sindical; y respeto a la propiedad, solamente expropiable mediante indemnización, si bien reconociendo la función social de la propiedad. Royo instó a los monárquicos, a que, si eran patriotas, dejasen obrar a los partidarios la República conservadora, pues les alertaba que si ésta fracasaba vendría el fascismo o el anarquismo ${ }^{7}$.

En cuanto a organización territorial, el manifiesto fundacional agrario abogaba por la defensa de «la unidad nacional, que considera intangible, sin prescindir de aquellas concesiones de descentralización administrativa autorizadas en la Constitución y que respondan a la variedad regional del territorio español»8. EI PAE no llegó a diseñar de manera precisa un modelo territorial y, en la práctica, apostó clara y decididamente por un descarnado centralismo. Así, Martínez de Velasco, en el mitin de presentación del partido, celebrado el 4 de febrero en el Teatro Victoria de Madrid, afirmó:

«Unidad nacional sin disgregaciones de ninguna clase. Somos partidarios de la autonomía y descentralización administrativas de municipios y regiones. Pero separación de la Patria, no. La Patria es una e intangible y no puede admitirse que se la discuta, porque la Patria es como la madre, y el que las discuta, merecería la pena de no haberlas conocido».

\footnotetext{
${ }^{5}$ PARTIDO AGRARIO ESPAÑOL: Op. Cit., pag. 3

${ }^{6} A B C, 26$ de enero y 1 de febrero de 1934.

7 El Debate, 17 de abril de 1934.

8 PARTIDO AGRARIO ESPAÑOL: Op. Cit., pag. 4.
} 
Martínez de Velasco aclaró, en cualquier caso, que el PAE respetaría el régimen vigente de los estatutos de autonomía ${ }^{9}$. En este sentido, tras la rebelión de la Generalidad catalana de octubre de 1934, el PAE pactó con la CEDA y el PRR la suspensión momentánea del Estatuto de Cataluña, desoyendo las tesis de Royo Villanova - que había encabezado una dura campaña en contra del Estatuto durante el primer bienio-, partidario de reformarlo.

Conviene señalar que el ideario del PAE contenía un cierto matiz castellanista. Celso Almuiña ha señalado que éste puede ser considerado un partido regionalista castellano sui generis por dos razones: tener «prácticamente todas sus bases» en Castilla la Vieja y León (regiones por las que fueron electos la mayoría de sus diputados); y consistir su propaganda en "una versión, más radicalizada» de la defensa de los «auténticos intereses» de Castilla, identificados con los de los terratenientes cerealistas y la burguesía harinera ${ }^{10}$. En este sentido, la bandera del PAE propuesta por un colaborador de Horizontes era una curiosa síntesis de agrarismo, castellanismo y catolicismo:

«El diseño propuesto es: seda amarilla, como las rubias espigas doradas por el padre Sol; en el centro, un rombo morado como el glorioso pendón de Castilla, la fecunda, la noble, la esforzada, la siempre preterida; campando sobre el rombo, la cruz, signo de fe, bordado en oro, blasón de pujanza, progreso y prosperidad» ${ }^{11}$.

El castellanismo del PAE no se quedó en mera retórica sino que tuvo ocasión de hacerse patente en mayo de 1936, cuando sus diputados secundaron la iniciativa, impulsada por la CEDA, de elaborar un Estatuto de Autonomía para Castilla y León ${ }^{12}$.

Sin embargo, resulta algo exagerado considerar al Partido Agrario Español una organización castellanista. Conviene recordar, en este sentido, que, más allá de la Meseta Norte, gozó de una implantación consolidada —al menos, en términos electorales- en provincias de Andalucía, Aragón, Castilla la Nueva y Galicia. De hecho, sólo seis de los trece agrarios electos en febrero de 1936 procedían de Castilla la Vieja y León. Por otra parte, la concepción de Castilla que tenía el PAE no difería apenas de la predominante entre la derecha: la de esencia y artífice de España. En este contexto, la apuesta de los agrarios por la autonomía en la primavera de 1936 puede interpretarse como un intento de levantar su imagen ante la opinión pública castellana al tiempo que una réplica a los procesos estatutarios que se estaban desarrollando en otras regiones.

\footnotetext{
9 El Debate, 6 de febrero de 1934.

10 Almuiña, C.: «Castilla ante el problema nacionalista durante la República. El Estatuto castellano non nato» en Beramend, J. G. y Maíz, R. (comps.): Los nacionalismos en la España de la II República, Madrid, Siglo XXI y Concello da Cultura Galega, 1991, pag. 436.

11 PÉReZ FernándeZ, J. A.: «La bandera agraria. Réplica por alusiones», Horizontes, 19 de febrero de 1935.

12 El Debate, 20, 22 y 23 de mayo de 1936.
} 
Otra de las principales señas de identidad del Partido Agrario Español fue, desde el comienzo, la defensa del robustecimiento del principio de autoridad. En febrero de 1934 Martínez de Velasco declaraba:

«Sube el rubor a las mejillas pensando que es indispensable colocar en el programa de un partido político el restablecimiento del principio de autoridad. Cuando este principio falla, es que se va a la anarquía. La autoridad es base indeclinable del orden, que permite a millares de ciudadanos, con intereses contrapuestos, conducirse como un solo ciudadano en la justicia y en la ley. La autoridad entraña una superioridad que impone la obediencia y un amor que impulsa a la veneración» ${ }^{13}$.

Un año más tarde, el líder agrario precisaba que, en caso de llegar al poder, esa defensa del principio de autoridad podría llegar «hasta la suspensión de partidos que no sólo cuentan en su programa con principios demagógicos, sino que alardean, a voz en grito, de sus intenciones revolucionarias y de sus hechos de idéntico tipo", en una clara alusión al PSOE. Instaba, en este sentido, al Ejecutivo a actuar con firmeza:

«Si no se tiene conciencia de esto, consintiendo revoluciones sin desarticularlas luego implacablemente, no se ha hecho nada, y si no sirve para eso el Gobierno, no sirve para nada más que para envilecerse, ésa es la palabra, que no la pienso retirar, y si no se ve o no quiere verse la responsabilidad que se contrae, que se deje paso a otros ${ }^{14}$.

La defensa a ultranza del principio de autoridad tuvo en José María Cid a su más claro exponente entre los agrarios, como demostró su gestión al frente del ministerio de Comunicaciones, caracterizada por un duro enfrentamiento con los sindicatos socialistas. No obstante, se reflejó también en otras actuaciones del PAE: la demanda de firmeza al Gobierno de Ricardo Samper en el pleito suscitado con la Generalidad de Cataluña y los ayuntamientos vascos en el verano de 1934; la oposición a la amnistía para el dirigente socialista de la revolución de octubre Ramón González Peña en marzo de 1935; y, meses antes de la Guerra Civil, la constante petición de restablecimiento del orden público al Gobierno de Santiago Casares Quiroga.

El programa provisional del PAE señalaba que el respeto del principio de autoridad había de ir acompañado del «máximo prestigio a los Institutos armados encargados de conservar y restablecer el orden público, que han de ser garantía para las personas y propiedades en el campo ${ }^{15}$. Es decir, afirmaba, sin demasiado disimulo, que la finalidad prioritaria de la acción de la fuerza pública debía ser la defensa de los intereses de los terratenientes. Conviene señalar que, con motivo de

13 El Debate, 6 de febrero de 1934.

14 Horizontes, 12 de febrero de 1935.

15 PARTIDO AGRARIO ESPAÑOL: Op. Cit., pag. 6 
la discusión en las Cortes del proyecto de ley de yunteros del cedista Manuel Giménez Fernández, Royo Villanova instó a los propietarios rurales a no olvidar a la Guardia Civil y a armarse «hasta los dientes» ${ }^{16}$.

\section{POLÍTICA EXTERIOR}

En materia de relaciones internacionales, el manifiesto del PAE abogaba por una «política de paz», basada en la organización de «un Ejército y una Marina reducidos, pero dotados de la máxima eficacia técnica, la garantía de su independencia» ${ }^{17}$. En este punto los agrarios coincidían, a grandes rasgos, con otras formaciones republicanas centristas y conservadoras ${ }^{18}$.

Los agrarios no consideraban el pacifismo incompatible con una potenciación de las Fuerzas Armadas con fines defensivos. Fue una idea presente en varios artículos aparecidos en la primavera de 1935 en Horizontes. Concretamente, Martínez de Velasco llamó la atención sobre la coyuntura internacional, marcada por el rearme de las potencias y advirtió que España debía mantener su neutralidad pero sin descuidar una adecuada política defensiva. Por este motivo, «mediante la autoridad insuperable de los técnicos", debía procederse sin demora a la organización de las defensas de las costas y del interior, así como de las islas, para lo cual se antojaba necesario coordinar las fuerzas de tierra, mar y aire. El líder agrario defendía, para el cumplimiento de estos fines, la aprobación por las Cortes de cuantos créditos fuesen «precisos para la defensa que nuestra vida nacional requiere» e instaba al Gobierno a hacer, con vistas a lograr ese objetivo, un «sacrificio" similar al que estaba haciendo para remediar el paro forzoso. No debían, a su juicio, temerse «recelos ni envidias» ajenas, pues dicho sistema defensivo habría de unir otros intereses «a los nuestros y contribuir a una convivencia en signo de amistad», especialmente con las naciones del "mar latino». Alertaba, además, sobre el «visible y constante aumento de las fuerzas militares soviéticas», cuando esa misma nación difundía «engañosos conceptos de humanitarismo para que sean disminuidos los contingentes de las demás naciones", por lo que no debían pasarse por alto aquellos pactos que la URSS suscribiera ${ }^{19}$.

En la misma línea que Martínez de Velasco se pronunció el colaborador de Horizontes Benjamín Marcos, para quien España, a pesar de haber renunciado a la guerra como instrumento de política nacional —según rezaba el artículo $6 .^{\circ}$ de la

16 Diario de Sesiones de las Cortes, 24 de noviembre de 1934, pag. 4918.

17 PARTIDO AGRARIO ESPAÑOL: Op. Cit., pag. 4.

18 La postura del PRC, el PRP y el PRLD en IÑIGo FERNÁNDEZ, L.: Op. Cit., pag. 243. En cuanto al PRR, Diego Hidalgo, ex-ministro de la Guerra, defendía un plan de defensa nacional compatible, a su juicio, con la renuncia a la guerra que hacía la República española en su Constitución. Ver HIDALGO, D.: ¿Por qué fui lanzado del Ministerio de la Guerra? Diez meses de actuación ministerial, Madrid, EspasaCalpe, 1934, pags. 185-187.

19 Martínez de Velasco, J.: «El problema económico y la situación internacional», Horizontes, 4 de abril de 1935. 
Constitución - debía seguir el adagio latino «si vis pacem, para bellum». En consecuencia, proponía un refuerzo de la defensa marítima basada medidas como la unificación de los cuerpos de Infantería, Marina y Aviación militar en un mismo ministerio, la institución del servicio militar obligatorio para todos los ciudadanos (pues aún permanecía el sistema de redención del servicio mediante el pago de una suma), la creación de unidades aptas para las defensas de las costas -en concreto de una aviación abundante y submarinos, torpederos y cazatorpederos-y la fortificación de los archipiélagos ${ }^{20}$.

Defendía Benjamín Marcos que España se preparase para, en caso de conflicto internacional, ser capaz de autoabastecerse. Proponía, por ello, diversas actuaciones: «una intensificación eficaz de las explotaciones mineras para poder producir y fabricar hierros y aceros para nuestros barcos, para nuestros aeroplanos, para nuestros submarinos, para la creación y fabricación de gases asfixiantes, para nuestros cañones, nuestros fusiles»; la fabricación de «material para automóviles, bicicletas, instrumental científico y herramientas»; la producción de «específicos y medicamentos", para no depender del extranjero; y el incremento de las fábricas de cuero, mantas y pañería ${ }^{21}$.

A principios de mayo de 1935, Marcos, tras aludir a los planes de rearme emprendidos en esos años por potencias como los EE UU, la URSS y Gran Bretaña, instó al Gabinete -en el que el líder cedista José María Gil-Robles y el agrario Royo Villanova desempeñaban respectivamente las carteras de Guerra y Marina- a emprender los siguientes proyectos: reorganización del Ejército y de la Marina, «para que resulten eficaces»; atención a la Marina mercante, como complemento de la militar; intensificación de industrias militares y su coordinación con las civiles; organización del Consorcio de fabricación y venta de armas; y, finalmente, fomento de aquellas industrias complementarias del abastecimiento nacional «con lo cual se atendería de una manera eficaz a remediar el paro obrero ${ }^{22}$. Desde el punto de vista de Marcos, los planes de rearme no veían dados sólo por razones defensivas sino también económicas y sociales, opinión compartida desde sectores políticos afines a los agrarios ${ }^{23}$.

Las ideas expuestas desde las páginas de Horizontes no cayeron en saco roto. Así, en septiembre de 1935, Royo Villanova se pronunció, desde su puesto de ministro de Marina, a favor de un plan de defensa nacional y remarcaba que se había presentado al Congreso un plan de fortificación de las Baleares. «No queremos una neutralidad inerte y pasiva, sino una neutralidad dotada de una gran fuerza material», afirmó24.

20 Marcos, B.: «Lo que urge más. Nuestra defensa marítima», Horizontes, 9 de abril de 1935.

${ }^{21}$ MARCos, B.: «Lo más urgente. Entre la guerra y la paz», Horizontes, 30 de abril de 1935.

${ }^{22}$ MARCos, B.: «Entre la paz y la guerra. Lo más urgente. A los ministros de defensa nacional», Horizontes, 14 de mayo de 1935.

${ }^{23}$ Ver HiDALGO, D.: Op. Cit., pags. 185-186.

${ }^{24}$ Ahora, 20 de septiembre de 1935. 
Esta apuesta por el refuerzo del Ejército derivaba, en el fondo, de una postura escéptica respecto las vías pacíficas para la resolución de los conflictos. En un acto de las Juventudes Agrarias -integradas en el PAE-, el general Francisco Martín Llorente destacó la inutilidad de los esfuerzos hechos a lo largo de la Historia para evitar las guerras y recordó, en este sentido, que la estatua de la Justicia empuñaba junto a la balanza una espada, para hacer cumplir el Derecho. Por este motivo, defendió la instrucción militar obligatoria, la creación de oficiales de complemento y la organización de un ejército diminuto y muy móvil, que pudiese servir de escuela de mandos así como de vivero de cuadros necesarios para una movilización en masa de la población ${ }^{25}$.

Al igual que Martín Llorente, José Antonio Pérez Fernández, capitán retirado, sostenía que sólo la existencia de un Ejército fuerte respaldaría las reivindicaciones de España en la escena internacional. Partía, igualmente, de la premisa de considerar el uso de la fuerza como el sostén, en última instancia, del Derecho:

«Nuestros equipos de negociadores de Tratados comerciales van bien provistos de razones y pruebas estadísticas; van saturados de patriotismo y ansias de vencer en la desigual contienda; pero... ¿qué poder militar y marítimo sostiene sus razones? ${ }^{26}$.

La postura a favor del reforzamiento del Ejército iba acompañada, en ocasiones, de la demanda de una política exterior más activa. El citado Martín Llorente lamentó que España no hubiese cumplido la intención de Isabel la Católica de conquistar el norte de África hasta el Atlas, como igualmente había aconsejado Cánovas del Castillo. Por ello, defendía el trueque de la zona española de Marruecos por «algo de más substancia», mediante negociación con Francia y Gran Bretaña ${ }^{27}$.

Por otra parte, desde el PAE —al igual que desde otras formaciones afines, como el PRC ${ }^{28}$ - se abogó por estrechar las relaciones con Hispanoamérica. En concreto, Julio Cola, colaborador de Horizontes, defendió una reforma de la Constitución para que los ciudadanos hispanoamericanos que pisaran suelo español adquiriesen la ciudadanía española, cada nación hispanoamericana tuviera derecho a enviar un diputado a las Cortes españolas y las importaciones hispanoamericanas quedaran exentas del pago de aranceles al ser introducidas en España ${ }^{29}$. El objetivo pretendido por Cola sería la conformación de una alianza entre España e Hispanoamérica que sirviera de contrapeso a la enorme influencia de Estados Unidos y de Gran Bretaña en esa región ${ }^{30}$.

25 Horizontes, 21 de enero de 1935.

26 Pérez FernándeZ, J. A.: «Colaboraciones espontáneas. El Derecho y la fuerza», Horizontes, 30 de abril de 1935.

27 Horizontes, 21 de enero de 1935.

28 IÑIGo FERnÁNDEZ, L.: Op. Cit., pag. 245.

29 COLA, J.: «Política de ultramar. ¿Deben considerarse los hispanoamericanos como extranjeros en España?», Horizontes, 12 de marzo de 1935.

30 ColA, J.: «Política de ultramar. Afirmación de una política común a España y América», Horizontes, 16 de abril de 1935. 


\section{ECONOMÍA}

El ideario del Partido Agrario Español prestó una especial atención a los aspectos económicos, particularmente a los relacionados con el campo. No en vano, proclamaba, en su manifiesto fundacional, «su orientación económica, a base de la defensa y fomento de la riqueza nacional en todas sus manifestaciones, y en especial de la producción agrícola, forestal y ganadera, que estima es el sostén de la economía española, cuyo progreso depende de la acertada coordinación de las diversas fuerzas productoras» ${ }^{31}$.

EI PAE conjugaba de manera un tanto contradictoria, la defensa del librecambismo con la exigencia de una política proteccionista de los productos agrarios nacionales. Así, mientras reconocía el «principio de libertad de comercio», reclamaba la «estabilidad del régimen arancelario, que ha de fijar derechos protectores a la producción agrícola y pecuaria, en armonía y proporcionalidad con los que graven las manufacturas industriales», así como «la prohibición de importaciones con derechos reducidos de productos agrícolas que puedan ocasionar depreciaciones ruinosas para los labradores". En este sentido, planteaba la posibilidad de que el Estado interviniera «por medio de la instauración de silos y paneras sindicales», a fin de que los excedentes de los años abundantes pudieran compensar la escasez de futuras recolecciones. Sobre el posible establecimiento de tasas para el cereal, se advertía que las mínimas no podrían ser inferiores al coste de producción ni las máximas al del precio de los productos similares extranjeros ${ }^{32}$.

Desde las páginas de Horizontes llegó a considerarse el establecimiento de la tasa en los cereales como «el principio más destructor de la producción» ${ }^{33}$. Sin embargo, los agrarios admitieron, como mal menor, el establecimiento de una tasa remuneradora del cultivo del cereal en aras, según afirmaron, de los intereses de los agricultores, en especial de los trigueros. Ursicino Gómez Carbajo, subsecretario de Obras Públicas, escribió en febrero de 1935:

«El Partido Agrario tiene entre sus deberes [...] atender, sea como sea, a que los productos del campo [...] alcancen precios suficientemente remuneradores, para que con el mayor valor de dichos productos se incremente el poder adquisitivo de compra de la clase agraria, en beneficio de la industria y de la economía nacional» ${ }^{34}$.

Igualmente, Martínez de Velasco afirmó, en febrero de 1935, ante la Asociación de Agricultores de España, que, pese a que no creía en ella, la tasa del trigo debía cumplirse una vez que se había fijado. Igualmente abogaba por que el Estado absorbiese el exceso de trigo, reservándolo para el momento en que fuera menor la producción ${ }^{35}$.

31 PARTIDO AGRARIO ESPAÑOL: Op. Cit., pag. 3.

32 PARTIDO AGRARIO ESPAÑOL: Op. Cit., pag. 5.

33 RuIz DE OJedA, M.: «Algo sobre el comercio de granos», Horizontes, 21 de enero de 1935.

34 Horizontes, 5 de febrero de 1935.

35 Horizontes, 12 de febrero de 1935. 
El objetivo claramente perseguido por los agrarios era garantizar la rentabilidad del cultivo del trigo, lo que debía lograrse reservando el mercado nacional para los productores cerealistas españoles, mayoritariamente castellanos. De hecho, la agricultura triguera nacional, arcaica y de baja productividad, difícilmente podía competir con la de países como EE UU, Rusia y Australia. La apuesta de los agrarios por el proteccionismo y el intervencionismo por parte del Estado tuvo se plasmó en sendas proposiciones de ley presentadas en las Cortes por la Minoría Agraria en mayo de 1934 y enero de 1935, en las que se pedía que el Estado —previa construcción de depósitos reguladores-adquiriese trigo por valor de 300 millones de pesetas $^{36}$ y en la ley de Autorizaciones impulsada por Nicasio Velayos desde su puesto de ministro de Agricultura y promulgada en junio de 1935, en virtud de la cual el ministro quedaba facultado para retirar 400.000 toneladas de trigo ${ }^{37}$. Tanto Velayos como Martínez de Velasco, su sucesor en el puesto, fracasaron en la búsqueda de una solución al problema triguero y favorecieron, en la práctica, los intereses de los harineros y de los grandes propietarios, que podían almacenar el cereal para venderlo en épocas de menor oferta. Ello les acarreó una notoria impopularidad en las áreas rurales cerealistas, que tendría su reflejo electoral en febrero de 1936.

Con vistas a favorecer el comercio nacional de los productos agrícolas y pecuarios, el PAE reclamó la modificación de las tarifas de transportes así el desarrollo de obras públicas como caminos secundarios ${ }^{38}$. Debe tenerse en cuenta que eran precisamente las regiones periféricas, como Cataluña, mal comunicadas con la Meseta, las que tendían más a la importación de trigo extranjero.

Otras propuestas del PAE relacionadas con la protección de la economía agraria fueron: la construcción de obras de regadíos y pantanos; la atención preferente por el Estado a la repoblación forestal; y la intensificación del crédito agrícola, mediante la ayuda de los bancos oficiales, la creación del Banco Nacional Agrario y la protección a los Pósitos y las Cajas rurales de responsabilidad solidaria $^{39}$. La primera de ellas recogía, al igual que otras corrientes políticas del momento, la herencia del pensamiento de Costa en lo relativo al fomento de una agricultura de regadío. No en vano, Cid, durante su etapa al frente del ministerio de Obras Públicas, continuó con las obras hidráulicas emprendidas por su antecesor Indalecio Prieto y su colaborador Manuel Lorenzo Pardo. La segunda propuesta se plasmó en el proyecto de ley de creación del Patrimonio Forestal del Estado, presentado a las Cortes por Velayos durante su etapa al frente del ministerio de Agricultura y aprobado poco después de su salida ${ }^{40}$. Finalmente, el impulso al crédito agrícola - cuya finalidad era la obtención del respaldo de los pequeños y medianos labradores, dependientes con frecuencia de los usureros- se concretó en

36 Diario de Sesiones de las Cortes, 24 de mayo de 1934, pag. 3.087 y 25 de enero de 1935, pags. 5.487-5.489.

37 Diario de Sesiones de las Cortes, 11 de junio de 1935, apag. 2.

38 PARTIDO AGRARIO ESPAÑOL: Op. Cit., pags. 5-7.

39 PARTIDO AGRARIO ESPAÑOL: Op. Cit., pag. 5.

40 Diario de Sesiones de las Cortes, 9 de octubre de 1935, apag. 1. 
las gestiones llevadas a cabo por Martínez de Velasco ante representantes de la Banca privada en el otoño de 1935 con el fin de conseguir préstamos para los agricultores con el trigo como garantía ${ }^{41}$.

Respecto a la industria y el comercio, el PAE prometió en su programa defender sus intereses, evitando la lucha de clases, «mediante la implantación de una legislación social exenta de sectarismo y en que se hermanen las aspiraciones legítimas de los trabajadores con los derechos del capital, sin exceder las posibilidades económicas de los distintos sectores de la opinión »42.

Contrariando la defensa del libre comercio proclamada por el partido, desde Horizontes se reivindicó una potenciación de la industria nacional, con el propósito de que España pudiera ser autosuficiente. Así, Julio Cola lamentaba que algunas industrias necesarias para España - químicas, de maquinaria y aparatos, de papel y derivados, de madera - se mostrasen enclenques al carecer de protección oficial. Reclamaba, por ello, un plan de industrialización que favoreciese su nacimiento, alertando de que si España tuviera que batirse en guerra, dependería de otra potencia que le abasteciera de aceros especiales para la construcción de maquinaria y herramientas ${ }^{43}$.

Por otra parte, el citado Benjamín Marcos, en una conferencia pronunciada en febrero de 1935, abogó por una mayor implicación del Estado en la minería, a la que calificó de «base del resurgimiento económico de España». Planteó la creación de un organismo «oficioso, no oficial», que, bajo la inspección estatal, se encargaría de encauzar los trabajos de investigación, explotación y extracción de minerales, selección de minas y productos, implantación de las necesarias industrias derivadas de tales explotaciones y aportación del capital necesario para toda esta labor. A su juicio, la creación de dicho organismo permitiría un gran incremento tanto de la producción minera como de las industrias derivadas de ésta, lo que reportaría importantes ingresos para el Estado y contribuiría a acabar con el problema del paro obrero e, incluso, a revertir la corriente migratoria ${ }^{44}$.

\section{SOCIEDAD}

En el terreno social el PAE adoptó una óptica muy conservadora, que se concretó en una apuesta por el restablecimiento del statu quo económico y laboral existente a la llegada de la República, en la defensa de los derechos de la Iglesia católica y en la conformidad con la subordinación de la mujer.

Sobre la cuestión sociolaboral en el campo, el manifiesto del PAE, tras «estimar la propiedad de la tierra como una función social», defendía el fomento «del

41 El Debate, 15 y 18 de septiembre y 8, 9, 16 y 23 de octubre de 1935.

42 PARTIDO AGRARIO ESPAÑOL: Op. Cit., pag. 7.

43 ColA, J.: «Aspecto de la producción española», Horizontes, 5 de febrero de 1935.

44 Horizontes, 12 de febrero de 1935. 
buen cultivo, llegando hasta decretar la expropiación, indemnizada, de las fincas no explotadas y garantizando, en cambio, al terrateniente de las bien cultivadas el tranquilo disfrute de su propiedad». El fin debía ser la «creación de la máxima población rural de pequeños y medianos propietarios, protegiendo con medidas económicas y fiscales el cultivo de la tierra por los propietarios» así como «reglamentando el contrato de arrendamiento a fin de que su regulación jurídica se armonice en los dictados de la ciencia agronómica para asegurar el máximo rendimiento técnico y abrir cauce legal al desarrollo del contrato de aparcería». Los agrarios admitían, además, una legislación tendente «a la división de los latifundios con destino a la creación de pequeños propietarios, siempre mediante la justa indemnización a los dueños y por motivos de mejor explotación económica»45.

EI PAE se mostraba dispuesto a aceptar una reforma agraria, aunque no tanto por razones de justicia social como de rentabilidad económica. Lo cierto es que cuando el agrario Nicasio Velayos estuvo al frente del ministerio de Agricultura, optó por impulsar una revisión en profundidad de la ley de 1932 que anuló, en la práctica la reforma, favoreciendo sin recato —al menos, a corto plazo- los intereses de los grandes propietarios. Además, la Minoría Agraria - con la notable excepción de Pedro Martín y Martín- luchó, denodadamente y con éxito, para que el proyecto de ley de Arrendamientos rústicos presentado a las Cortes por Giménez Fernández fuese despojado de sus aspectos más progresistas y favorecedores del arrendatario.

Sólo en lo relativo al contrato de aparcería mostró el PAE cierto aperturismo, por medio de su diputado Martín y Martín. Éste trató, infructuosamente, de introducir en el citado proyecto de ley de Arrendamientos algunas modificaciones en favor del aparcero: concretamente, pidió que se le concediesen, al igual que al arrendatario, los derechos de prórroga del contrato y de retracto en caso de venta de la finca ${ }^{46}$.

EI PAE defendió, igualmente, en su programa provisional, la revisión de gran parte de la legislación sobre el campo dictada en el primer bienio. Pedía expresamente la «derogación de las leyes que limitan el reclutamiento de la mano de obra», en alusión a la ley de Términos Municipales aprobada en 1931, y la «separación de los Jurados mixtos del campo en toda actuación sectaria para convertirlos en órganos imparciales de Justicia social» ${ }^{47}$. El fin real de propuestas era defender los intereses de los grandes propietarios. La primera de ellas — con la que se mostraban de acuerdo la patronal agraria y otros partidos no sólo de la derecha sino también del centro republicano- fue, durante los primeros meses de 1934, una exigencia constante de los agrarios a los Gobiernos de predominio radical hasta su aprobación en las Cortes en mayo de dicho año. En cuanto a la se-

45 PARTIDO AGRARIO ESPAÑOL: Op. Cit., pag. 6.

46 MARTín y MARtín, P.: «Temas nacionales. Sobre el contrato de aparcería», Horizontes, 5 de marzo de 1935.

47 PARTIDO AGRARIO ESPAÑOL: Op. Cit., pag. 6. 
gunda, cabe señalar que, tras el verano de 1935, los Jurados Mixtos del Trabajo Rural pasaron a control de los terratenientes ${ }^{48}$.

Se proponían, además, en el manifiesto del PAE una serie de medidas que elevaran el nivel de vida material e intelectual de la población rural sin modificar su statu quo socioeconómico: la mejora de las condiciones sanitarias del campo mediante el abastecimiento de aguas potables, la lucha contra el paludismo y la modernización de las viviendas. Sobre este punto, el PAE se mostraba favorable a que el Estado protegiera a las empresas que tendieran a suministrar energía eléctrica para el alumbrado y las industrias agrícolas de los pequeños núcleos de población (no hay que olvidar que José María Cid era miembro del Consejo de Administración de la empresa hidroeléctrica El Porvenir, de Zamora). Igualmente, abogaba por un impulso de la enseñanza agrícola a cargo del Estado en todos sus grados, desde la escuela primaria, con especial atención a las cátedras ambulantes, así como el establecimiento de campos de demostración, reglamentando los concursos agrícolas y ganaderos ${ }^{49}$. Todas estas reivindicaciones - al igual que la de construcción de caminos, canales y pantanos- tenían claros resabios regeneracionistas.

La mayoría de las ideas del PAE para el mundo rural quedaron en papel mojado. Sólo la relativa al suministro de agua potable se plasmó en una proposición de ley presentada por la Minoría Agraria en las Cortes el 22 de febrero de 1934 y defendida por el diputado por Burgos Ángel García Vedoya. En el texto de la misma se declaraba función del Estado la ejecución del abastecimiento de aguas y saneamiento de los núcleos rurales que aún no los poseyesen. En concreto, el ministerio de Obras Públicas realizaría un plan de abastecimiento de aguas que sería costeado por el Estado, en un $100 \%$ en el caso de los pueblos menores de 1.000 habitantes y en un $75 \%$ en el de los municipios cuya población oscilara entre 1.000 y 4.000 . En las poblaciones que pasaran de esta cifra se dejaría a la iniciativa municipal la ejecución de los abastecimientos de aguas ${ }^{50}$.

Respecto a las relaciones laborales en el comercio y la industria, el PAE prometía evitar «la lucha de clases, que tantos perjuicios ocasiona a estas importantes ramas de la economía nacional, mediante la implantación de una legislación social exenta de sectarismo y en que se hermanen las aspiraciones legítimas de los trabajadores con los derechos del capital ${ }^{51}$.

Con ese propósito de armonizar los intereses de obreros y empresarios, no faltó quien se remitió a la doctrina social de la Iglesia. José Canalejas, miembro del Consejo Central Directivo del PAE, advirtió que los ricos debían cumplir con las disposiciones pontificias al respecto si querían evitar «revoluciones y trastornos», de-

48 MALEFAKIS, E.: Reforma agraria y revolución campesina en la España del siglo xx, Barcelona, Ariel, 1980, pags. 415-416.

49 PARTIDO AGRARIO ESPAÑOL: Op. Cit., pags. 6-7.

50 Diario de Sesiones de las Cortes, 22 de febrero de 1934, pags. 1134-1135.

51 PARTIDO AGRARIO ESPAÑOL: Op. Cit., pags. 7. 
fendió que el obrero fuese un asociado del capitalista - pues no debía tenerse en cuenta solamente el valor del producto del trabajo sino las necesidades del obrero y su familia- y juzgó la intervención del Estado en la cuestión social beneficiosa tanto para trabajadores y patronos ${ }^{52}$.

Sin embargo, planteamientos como el de Canalejas fueron más la excepción que la norma dentro del PAE. Así, Alfredo Aleix, en la Cámara de Comercio de Madrid, señaló como causas del aumento del paro en la industria la subida de los jornales - que no había ido acompañada, a su juicio, de la de la productividad-, las huelgas ilegales, los atentados y actos de sabotaje contra los patronos - que obligaban a éste a dejar la empresa-, las bases de trabajo y la actuación de los Jurados Mixtos. Sobre el desempleo en la agricultura, señaló como factores del mismo la legislación del primer bienio y las «predicaciones extremistas». Las soluciones propuestas por él fueron: el restablecimiento del «principio de autoridad»; la fijación de «salarios en relación con la potencialidad económica de la agricultura, el comercio y la industria»; la modificación de los Jurados Mixtos «para que sean útiles y no focos de propagandas extremistas»; la supresión del trabajo de la mujer con vistas al lujo personal, «mientras existen hombres que no pueden llevar pan a sus hogares" (lo que revelaba una visión tradicional del rol de la mujer); la «exención de tributos a las industrias de nueva creación», medida favorecedora de las iniciativas empresariales; la «educación profesional del obrero»; el fomento de la construcción por medio de capital barato; $y$, por último, la «eliminación de los trabajadores extranjeros ${ }^{53}$. Aleix abogaba, pues, por medidas que no cuestionaran en modo alguno el orden social establecido.

Puede decirse, por tanto, que, en materia laboral, el PAE trató de restablecer el statu quo existente a la llegada de la República en tanto favorecedor de los intereses de los empresarios. Varias de las medidas tomadas por gobiernos con representación agraria fueron en esa dirección. Un decreto promulgado el 1 de diciembre de 1934 puso fuera de la ley las «huelgas abusivas», es decir, las que no tuvieran un estricto carácter laboral o no contaran con autorización gubernativa. Durante el segundo bienio los presidentes de los Jurados Mixtos —organismos de arbitraje con representación obrera y patronal-, designados por el Gobierno, se mostraron más receptivos a los intereses empresariales. Tras la revolución de octubre, fueron provisionalmente suspendidos y en el verano de 1935 se modificaron sus funciones a fin de disminuir el poder de los vocales obreros. Mientras, los Jurados Mixtos del Trabajo Rural pasaron a control de la oligarquía agraria. Como consecuencia, se produjo un freno en el crecimiento de los salarios -o incluso su disminución en determinadas faenas-y un incremento de las jornadas laborales en sectores como la siderurgia ${ }^{54}$.

52 Horizontes, 26 de febrero de 1935.

53 Ahora, 23 de marzo de 1935.

54 Gil Pecharromán, J.: Historia de la Segunda República española, Madrid, Biblioteca Nueva, 2002, pags. 206-207 y MALEFAKIS, E.: Op. Cit., pags. 415-416. Cabe apuntar que en noviembre de 
Acerca de la cuestión religiosa, frente al anticlericalismo característico del primer bienio republicano, el PAE abogó, desde su fundación, por la revisión de «aquellos preceptos del Código fundamental que atentan a la conciencia religiosa del pueblo español», en alusión al artículo 26 de la Constitución, que prohibía a las órdenes religiosas dedicarse a la docencia. Propugnó, además, la concertación con la Santa Sede de un Concordato que, «sobre la base de la independencia de la Iglesia, regule sus relaciones con el Estado sin menoscabo de la libertad de conciencia a las minorías disidentes» ${ }^{55}$.

Para Martínez de Velasco, la firma de un Concordato no violaba la aconfesionalidad del Estado, como demostraba el firmado en 1921 por la República Francesa y la Santa Sede. El objetivo había de ser hacer compatible la separación entre Iglesia y Estado con la colaboración entre ambos poderes:

«El principio de libertad exige la separación entre la Iglesia y el Estado. No es esto cosa que aparezca en la Constitución por vez primera; tiene su fundamento en las palabras de Cristo en el Evangelio: Dad a Dios lo que es de Dios y al César lo que es del César. Pero los intereses del Estado y de la Iglesia se entrelazan, y procede buscar una zona de delimitación, que no puede ser de violencia sino de concordia, porque la separación no puede ser nunca antagonismo sino colaboración. Al Estado incumbe el orden material; a la Iglesia, el orden espiritual. No se concibe el uno sin el otro. Si no hay paz en los espíritus, no puede haberla en los cuerpos. La Historia nos demuestra que no hay nada tan revolucionario como las predicaciones antirreligiosas. El ejemplo más vivo de esta verdad nos lo ha ofrecido España»56.

La postura del PAE era, pues, similar a la de otras formaciones republicanas de orden, defensoras de la neutralidad del Estado en materia religiosa -lo que se traducía una separación entre éste y la Iglesia y la garantía por parte del primero de la práctica religiosa pública y privada - y del establecimiento de un Concordato ${ }^{57}$.

EI PAE no guardó, por otra parte, en su ideario una vinculación con la Iglesia católica tan estrecha como la que mantuvieron la CEDA — que, en cierto modo, actuaba como su brazo político- o la Comunión Tradicionalista. En las Cortes Constituyentes los agrarios liberales, si bien se opusieron a las medidas anticlericales - como el artículo 26 de la Constitución, la ley de Confesiones y Congregaciones o la disolución de la Compañía de Jesús-, lo hicieron en nombre del principio de libertad religiosa. El principal representante de esta tendencia fue Royo Villanova, quien recordaría que en 1910 tanto él como Martínez de Velasco habían entrado en el Parlamento en calidad de partidarios de la libertad de culto ${ }^{58}$. Llama,

1934 la Minoría Agraria había presentado una proposición de ley que introducía en la de Jurados Mixtos de 27 de noviembre de 1931 algunas modificaciones de procedimiento. Ver Diario de Sesiones de las Cortes, 22 de noviembre de 1934, pag. 4.943.

55 PARTIDO AGRARIO ESPANNOL: Op. Cit., pags. 3-4.

${ }^{56}$ El Debate, 6 de febrero de 1934.

57 IÑIGO FERNÁNDEZ, L: Op. Cit., pag. 241. El Concordato era algo deseable para el PRP y el PRLD, mientras que el PRC lo consideraba irrenunciable.

58 Ortega, T.: Presidente: Martínez de Velasco, Barcelona, Araluce, 1935, pags. 7-9. 
además, poderosamente la atención el hecho de que entre los diputados del PAE figurase un miembro de la Masonería: el burgalés Ramón de la Cuesta, que se habría iniciado en esta sociedad secreta en $1935^{59}$.

En cualquier caso, el catolicismo no fue ajeno al discurso político de los agrarios. Ello pudo constatarse tanto en la insistencia, durante los primeros meses de 1934, para que fuese aprobada una ley de Haberes del Clero como en varias de las declaraciones de sus líderes. En febrero de 1934, Martínez de Velasco afirmaba que las medidas anticlericales no habían modificado las creencias católicas del pueblo español:

«En política religiosa se ha olvidado en España la experiencia, se ha creído que consignar que el Estado no tenía religión bastaba para que la religión desapareciera del pueblo español. Dios vive constantemente en la naturaleza y en la sociedad. Cuando se le niega, se responde a su palabra; cuando se le rechaza, se responde a su presencia» ${ }^{60}$.

Cid, por su parte, en un banquete ofrecido por el PAE malagueño no dudó en proclamar el carácter católico del partido y en afirmar, además, que la catolicidad era algo que estaba en el «espíritu de la nación»61.

Incluso una figura de raigambre liberal como Royo Villanova se dejaría llevar, en ocasiones, por una encendida exaltación del catolicismo. En un mitin celebrado en marzo de 1935 en Málaga señaló una estrecha ligazón entre agrarismo y religiosidad:

«No es posible separar las actividades agrícolas de las frases religiosas, porque hasta el menos creyente no puede dejar escapar de sus labios más de una vez el deseo, en momentos difíciles, que se refleja en la frase Dios nos asista».

Royo Villanova se enorgulleció, incluso, de haber coincidido con los monárquicos alfonsinos y carlistas en la defensa del catolicismo. Para él la República debía proceder con los católicos «con la misma liberalidad» que había tenido la Monarquía con los no católicos, aunque añadiendo que el «error» no podía tener «los mismos derechos que la verdad» que representaba la doctrina católica. A su juicio, las medidas anticlericales eran fruto del temor al triunfo de esa verdad:

"Yo me explico la intransigencia de nuestros adversarios, porque ellos saben que con la libertad ganaremos nosotros siempre y es ése nuestro triunfo, lo que nos quieren quitar» ${ }^{62}$.

59 CRUz, J. I.: Masonería y educación en la II República española, Alicante, Instituto de Cultura Juan Gil Albert, 1993, pag. 247.

60 El Debate, 6 de febrero de 1934.

61 Horizontes, 5 de febrero de 1935.

62 Horizontes, 12 de marzo de 1935. 
Igualmente, en mitin celebrado en las mismas fechas en Ciudad Real, Royo llegó a definir al PAE como «partido religioso», mientras su correligionario Daniel Mondéjar afirmó tajante que sin la religión no se concebía la formación de España:

«[...] díganlo si no nuestras gestas y la visión de nuestros colonizadores y navegantes, y hasta modernamente, y ya en tiempos de escepticismo, la misma guerra de la Independencia es consecuencia de otro hecho religioso, vinculado a la defensa de la Patria. La Virgen del Pilar no quiere ser francesa y un muro infranqueable se opone al avance de las tropas napoleónicas ${ }^{63}$.

El catolicismo estaba, además, presente en las actividades y en la propaganda desarrolladas del PAE: sus sedes eran bendecidas por sacerdotes, sus dirigentes no olvidaban la asistencia a misa en sus frecuentes giras por España y la fiesta del partido, celebrada el 15 de mayo — día de San Isidro, patrón de la agricultura-, incluía una misa en la ermita de San Antonio de la Florida de Madrid.

La escasa simbología del PAE que se conoce contenía, igualmente, referencias cristianas. La bandera propuesta desde las páginas de Horizontes en febrero de 1935 contenía la cruz cristiana en el centro. Meses más tarde, el emblema que figuraba en la cabecera del Boletín del Partido Agrario Español consistía en el escudo de España sobre la cruz y flanqueados ambos por una espiga de trigo y una rama de olivo y por las iniciales «P» $y$ « $A$ » (correspondientes a Partido Agrario).

EI PAE llegó, incluso, a aplicar una terminología religiosa a su actividad. Así, en un mitin en Sevilla, Martínez de Velasco comentó, al hilo de la supuesta discriminación de los militantes del partido por las autoridades provinciales, que «sentía una viva satisfacción, porque la política debe ser una religión y no hay religión sin mártires " ${ }^{64}$. Ejemplo de la adopción de un lenguaje religioso lo constituyó la serie de artículos escritos en Horizontes por M. González en los que comparaba al PAE con «una nueva religión política» que tenía como base la defensa de la agricultura y que, al igual que el cristianismo, se había forjado en un ambiente hostil -las Cortes Constituyentes - y estaba dirigida por una «Trinidad augusta», en la que Martínez de Velasco era el Padre, Cid el Hijo y Royo Villanova el Espíritu Santo ${ }^{65}$. Contaría, asimismo, con su Credo y su Decálogo ${ }^{66}$, sus virtudes ${ }^{67}$ y sus dogmas ${ }^{68}$.

Relacionado con la cuestión religiosa estaba el problema de la enseñanza. De hecho, el artículo 26 de la Constitución había indignado a la opinión católica al prohibir la docencia a las órdenes religiosas. EI PAE, en su manifiesto, abogaba

63 Horizontes, 26 de marzo de 1935.

64 Horizontes, 21 de enero de 1935.

65 GonzÁlez, M.: «Por qué soy agrario. Una nueva religión política», Horizontes), 5 de marzo de 1935.

66 GonZÁLEZ, M.: «Por qué soy agrario. Esta nueva religión política tiene su Credo y su Decálogo», Horizontes, 12 de marzo de 1935.

67 GonzÁLEZ, M.: «Por qué soy agrario. Las virtudes de esta nueva religión política», Horizontes, 19 de marzo de 1935.

68 GonzÁlez, M.: «Por qué soy agrario. Dogmas de esta religión política», Horizontes, 23 de abril de 1935. 
por el «fomento de la enseñanza pública, sin monopolios incompatibles con la libertad de enseñanza» ${ }^{69}$. Es decir, atacaba el concepto de escuela única y laica. En este sentido, es importante señalar que Martínez de Velasco ocupó la presidencia del Consejo de Administración de la Sociedad Anónima de Enseñanza Libre (SADEL). La SADEL fue una iniciativa de la Confederación Católica de Padres de Familia con el objetivo de fomentar y desarrollar la enseñanza confesional en España así como agrupar y dar cobertura legal a los colegios regentados anteriormente por religiosos. En septiembre de 1934 abarcaba 52 colegios que daban enseñanza a 16.318 alumnos $^{70}$.

No faltaron, entre los dirigentes agrarios, declaraciones en favor de la educación católica. Así, Royo Villanova, en un acto celebrado en Málaga en marzo de 1935, atacó la prohibición de la enseñanza religiosa preguntando: «¿Qué es más peligroso para la República, que se enseñe a los niños a amar a Dios o a odiar a España? ${ }^{71}$. En esta misma ciudad defendió, meses después, la libertad de los padres para escoger la educación de sus hijos y juzgó más importante la reforma del artículo 26 de la Constitución que la del $3 .^{\circ}$ (que establecía que el Estado español no tenía religión oficial) ${ }^{72}$.

Sobre el papel de la mujer, el PAE, en su manifiesto fundacional, mostraba su confianza en contar, para el cumplimiento de su programa político, con «el concurso de las Asociaciones femeninas, que verán reflejados en esta actuación los sentimientos arraigados de la mujer española ${ }^{73}$.

Parecían, pues, confiar los agrarios en el supuesto conservadurismo de las mujeres españolas, derivado de su mayor religiosidad y de la consiguiente influencia que sobre ellas ejercía la Iglesia. De hecho, el partido llegó a contar con una Sección Femenina, que, pese a su escasa importancia, era indicio de un afán por recabar el respaldo de las mujeres, siguiendo la línea emprendida con éxito por las organizaciones católicas, vinculadas, directa o indirectamente, a la CEDA.

Los planteamientos de la Sección Femenina del PAE eran muy conservadores. Su presidenta, Prado García Montón se mostraba disconforme con que la mujer restase campo al hombre en su desenvolvimiento profesional, aunque veía con buenos ojos que adoptase «una vida propia e independiente», a fin de ser «menos gravosa» a su marido; es decir, admitía una cierta liberación de la mujer, mas no por su interés sino por el de su cónyuge. García Montón advertía, por otra parte, a las mujeres de la posibilidad de que algún día quisieran arrebatarle a sus hijos «en nombre de una ley hecha por hombres sin corazón» —en alusión a la ley del divorcio-y les instaba a luchar por ellos «hasta perder la vida» ${ }^{74}$.

69 PARTIDO AGRARIO ESPAÑOL: Op. Cit., pag. 4.

70 Pérez Galán, M.: La enseñanza en la Segunda República Española, Madrid, Edicusa, 1975, pags. 295-297; Boletín del Partido Agrario Español, 25 de febrero de 1936.

71 Horizontes, 12 de marzo de 1936.

72 La Unión Mercantil, 25 de agosto de 1935.

73 PARTIDO AGRARIO ESPAÑOL: Op. Cit., pag. 5.

74 Horizontes, 9 de abril de 1935. 
Pese a la retórica tibiamente feminista empleada por las mujeres agrarias, desde el partido se siguió, en la práctica, defendiendo el rol tradicional femenino, basado en el desempeño de las labores domésticas y en la subordinación al marido. Buena muestra fue un artículo aparecido en el Boletín del Partido Agrario Español después de los comicios de 1936. En él se comenzaba por elogiar el importante papel desempeñado por la mujer en la campaña electoral:

«Entre los múltiples factores que han intervenido en las elecciones [...] figura de manera preeminente la mujer, no sólo con su sufragio personal al depositar el voto en las urnas, sino con su entusiasmo subyugante y contagioso; con su presencia alentadora en los mítines y conferencias; con su propaganda ya directa como oradora, ya indirecta como animadora de los actos públicos verificados; con su cooperación y trabajo en oficinas, centros electorales y comités, contribuyendo a las organizaciones de los partidos; hasta con su actividad en las calles y plazas, no sólo trabajando votos, sino repartiendo programas, manifiestos y candidaturas".

Sin embargo, tras ese reconocimiento, el articulista defendía su retorno a las tareas que consideraba propias de su género:

«Pero ya está bien: ya pasó el momento y no necesita demostrar más que para estos menesteres vale tanto la mujer como el hombre; ahora, ya, ni que hablar...; la mujer, a su casa, a su hogar, a sus quehaceres y labores, a su oficina, a su taller, a sus distracciones y pasatiempos: el carnaval que aguarda y, luego, la cuaresma... Se acabaron las discusiones, las conferencias, la euforia política. Que ha perdido mucho tiempo en perjuicio de las atenciones que los peques exigen, y hay que reponer muchos calcetines y planchar mucha ropa... Debe reintegrarse ya la mujer a su femineidad, a la integridad de su ambiente, a la paz y sosiego familiar» ${ }^{75}$.

Quizás para compensar el papel secundario asignado a las mujeres, fueron frecuentes las alabanzas a ellas vertidas por los dirigentes agrarios. En el acto de inauguración del primer domicilio social del partido, Royo Villanova calificó de "decisiva» la influencia de la mujer en la vida y Martínez de Velasco declaró que «todas las acciones, cuando son buenas, llevan por delante el espíritu femenino»"

Los políticos agrarios destacaron la religiosidad como característica femenina, en las misma línea que las derechas del momento. Concretamente Cid mostró su confianza en contar con el respaldo de las mujeres «cuyos sentimientos religiosos hemos servido ${ }^{77}$. En plena campaña electoral de 1936, el escritor y dirigente agrario malagueño José María Hinojosa afirmó que «si de las escuelas se arrancó el crucifijo, las madres españolas se lo echaron al pecho, mostrándolo a sus hijos " ${ }^{78}$. Hay que tener en cuenta que muchas mujeres cercanas al agrarismo militaban, además, en las organizaciones católicas. Un caso paradigmático fue Zamora, donde la Unión de Juventudes Femeninas de Acción Católica estuvo presidida por Carmen

\footnotetext{
${ }^{75}$ Boletín del Partido Agrario Español, 18 de febrero de 1936.

76 Ahora, 13 de enero de 1934.

77 El Debate, 15 de mayo de 1934.

${ }^{78}$ La Unión Mercantil, 15 de febrero de 1936.
} 
Cid y Ruiz-Zorrilla — hermana de José María Cid-mientras que la Junta Directiva de la Asociación Femenina de Educación Ciudadana permaneció durante un tiempo bajo control de las esposas y familiares de dirigentes del Partido Provincial Agrario, si bien terminó siendo dominada por la CEDA ${ }^{79}$.

\section{CONCLUSIÓN}

En razón de su ideario, el Partido Agrario Español representó, durante los años de la II República, una opción inequívocamente conservadora: así lo demostraban su intención de revisar la Constitución, su rechazo a la autonomía política regional, su defensa del principio de autoridad y su pretensión de modificar profundamente las leyes sociales del primer bienio. Sin embargo, a diferencia de otras fuerzas derechistas del momento, el PAE aceptó la República, con vistas a imprimirle un sello conservador, y trató de llevar a cabo su programa político mediante las vías legales, rechazando firmemente el recurso a la fuerza. Sin embargo, debido tanto a lo obsoleto y endeble de su estructura organizativa - basada en las redes caciquiles características de la «vieja política»- como a la creciente polarización política de la sociedad española, sus posibilidades de éxito fueron muy escasas, desapareciendo definitivamente durante la Guerra Civil.

79 Mateos Rodríguez, M. A.: Zamora en la Il República. Comportamiento y actitudes de una sociedad tradicional: elecciones y partidos (1931-1936), Zamora, Instituto de Estudios Zamoranos Florián de Ocampo, 1995, vol. I, pags. 219-223. 